\section{RELATIONSHIP BETWEEN LIVING HABITS AND METABOLIC DISEASES IN COMMUNITY POPULATIONS BASED ON ULTRASOUND DIAGNOSIS OF NAFLD}

\author{
RELAÇÃO ENTRE HÁBITOS DE VIDA EDOENÇAS METABÓLICAS EM COMUNIDADES COM BASENA \\ DOENÇA HEPÁTICA GORDUROSA NÃO ALCOÓLICA (DHGNA) DIAGNOSTICADA POR ULTRASSOM

\section{DIAGNÓSTICO ULTRASÓNICO DELA RELACIÓN ENTRELOS HÁBITOS DE VIDA DE LA COMUNIDAD NAFLDY LAS ENFERMEDADES METABÓLICAS}

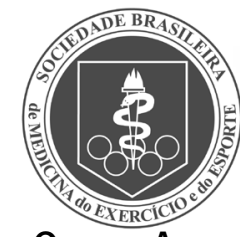

Original Article

ARTIGO ORIGINAL

ARTículo Original

\begin{abstract}
Hong Yue ${ }^{1,2}$ (D)
(National Traditional Sports)

Lixue Yin 1,3 (iD

(Sports dance)

1. School of Clinical Medicine, Southwest Medical University, Luzhou, China.

2. Nanchong Central Hospital, The Second Clinical Medical College, North Sichuan Medical College, Nanchong, China.

3. Department of Cardiovascular Ultrasound and Non-invasive Cardiology, Key Laboratory of Ultrasound in Cardiac Electrophysiology and Biomechanics of Sichuan Province, Sichuan Academy of Medical Sciences \& Sichuan Provincial People's Hospital, Chengdu, China.
\end{abstract}

Correspondence:

ybyvcc@163.com

\begin{abstract}
As a common metabolic disease, non-alcoholic fatty liver disease (NAFLD) is the most common type of liver disease in western developed countries and an important liver disease in the Asia Pacific region. At present, NAFLD lacks targeted conventional therapy and its basic treatment is the correction of bad living habits. In order to verify the effectiveness of the basic treatment of NAFLD, and explore the prevention methods of NAFLD, this study used ultrasound diagnosis, baseline survey and follow-up survey, and conducted a cross-sectional study on the correlation between nighttime and midday sleep duration and NAFLD, and carried out a prospective study on the correlation between sleep duration and NAFLD. The results showed that there was a negative correlation between the length of sleep at night and the prevalence of NAFLD, while the length of midday sleep was positively correlated with the prevalence of NAFLD. The time of night sleep was an independent factor of NAFLD, and the relationship between midday sleep time and NAFLD was not statistically significant. NAFLD-susceptible people can prevent NAFLD by ensuring adequate sleep at night and reducing midday sleep. This study is expected to provide theoretical reference and data support for the prevention and treatment of NAFLD.
\end{abstract}

Keywords: Utrassound diagnosis; NAFLD; metabolic diseases; sleep.

\section{RESUMO}

Como uma doença metabólica comum, a doença doença hepática gordurosa não alcoólica (DHGNA) é o tipo de doença hepática mais comum nos países desenvolvidos ocidentais e uma doença hepática importante na região Ásia Pacífico. Atualmente, a DHGNA carece de terapia convencional orientada, e seu tratamento básico é a correção de maus hábitos de vida. A fim de verificar a eficácia do tratamento básico da DHGNA e explorar os métodos de prevenção da DHGNA, este estudo, baseado no diagnóstico por ultrassom, através do inquérito de base e do inquérito de acompanhamento, consistiu de estudo transversal sobre a correlação entre a duração do sono à noite e de dia e a DHGNA, e realizou um estudo prospectivo sobre a correlação entre a duração do sono e a DHGNA. Os resultados mostraram que havia uma correlação negativa entre a duração do sono à noite e a prevalência de DHGNA, enquanto a duração do sono de dia estava positivamente correlacionada com a prevalência da DHGNA. A hora do sono noturno foi um fator independente de DHGNA, e a relação entre o sono de dia e DHGNA não foi estatisticamente significativa. As pessoas sensiveis à DHGNA podem prevenir a DHGNA garantindo o sono adequado à noite e reduzindo o sono de dia. Espera-se que este estudo possa fornecer referências teóricas e suporte de dados para a prevenção e tratamento da DHGNA.

Descritores: Diagnóstico ultrassonográfico; DHGNA; doenças metabólicas; sono.

\section{RESUMEN}

Como enfermedad metabólica común, la enfermedad del hígado graso no alcohólico (NAFLD) es el tipo más común de enfermedad hepática en los países desarrollados occidentales y una enfermedad hepática importante en la región de Asia que da al Pacífico. En la actualidad, la EHGNA carece de terapia convencional dirigida y su tratamiento básico es la corrección de los malos hábitos de vida. Con el fin de verificar la efectividad del tratamiento básico y explorar los métodos de prevención de la EHGNA, este estudio utilizó un diagnóstico por ultrasonido, una encuesta de referencia y una encuesta de seguimiento, condujo un estudio transversal sobre la correlación entre la duración del sueño nocturno y la siesta y la EHGNA, y realizó un estudio prospectivo sobre la correlación entre la duración del sueño y la EHGNA. Los resultados mostraron que hubo una correlación negativa entre la duración del sueño por la noche y la prevalencia de EHGNA, mientras que la duración de la siesta se correlacionó positivamente con la prevalencia de EHGNA. El tiempo de sueño nocturno fue un factor 
independiente de la EHGNA, y la relación entre el tiempo de siesta y la EHGNA no fue estadísticamente significativa. Las personas susceptibles a la EHGNA pueden prevenirla asegurando un sueño adecuado por la noche y reduciendo la siesta. Se espera que este estudio proporcione referencias teóricas y soporte de datos para la prevención y el tratamiento de la EHGNA.

Descriptores: Diagnóstico utrosonic; nafld; enfermedades metabólicas; sueño.

\section{INTRODUCTION}

Economic development enables people to have more opportunities to eat high sugar and high-fat food, and the progress of science and technology has greatly reduced the physical labor that people have to carry out in their daily life. Obesity caused by high energy intake and low energy consumption has become a major problem in developed and developing countries. Obesity, hyperlipidemia, hypertension, fatty liver, diabetes and a series of common diseases in modern people's life are caused by metabolic disorders. These metabolic diseases have a strong relationship with each other and usually exist in the human body at the same time. ${ }^{1}$ This series of interrelated metabolic diseases are important pathogenic factors of cardiovascular and cerebrovascular diseases, which are the leading cause of death in the world population. NAFLD is a member of the large family of metabolic diseases. Currently, NAFLD is lack of drugs that can be used for targeted conventional treatment. It can only be treated and relieved by controlling metabolic disorders. ${ }^{2}$ In modern society, people generally live under great pressure and have more entertainment. Therefore, a large number of people have the problem of insufficient sleep at night. According to the data from the National Health Survey of the United States, only $21.6 \%$ of the respondents sleep less than 7 hours in 1977, while in 2017, the proportion has increased to $40 \%{ }^{3}$ In order to explore the relationship between NAFLD and sleep deprivation, this study, based on the ultrasound diagnosis of NAFLD, conducted cross-sectional and prospective studies on the relationship between the living habits of the community population and the prevalence and incidence of NAFLD.

The team of perumpail Brandon J discussed the therapeutic or preventive effect of vitamin E on NAFLD. The research shows that vitamin E has significant therapeutic effect on NAFLD diabetes without diabetes mellitus, and the prognosis of patients is good. ${ }^{4}$ Omer s et al. Used ultrasound diagnostic methods to evaluate the impact of lipid-lowering agents on the risk of cardiovascular death in patients with NAFLD. Experiments showed that statins and other lipid-lowering agents did not significantly reduce the mortality of NAFLD or cardiovascular disease. ${ }^{5}$ Patton a et al. Established a model to prevent TLR4 (Toll like receptor 4) signal transduction induced by lipopolysaccharide and palmitate, and proposed that phenyl methyl imidazole is a potential drug of NAFLD. ${ }^{6}$ Ali Khan R and his colleagues used clinical research to explore the effect of orlistat on NAFLD obese patients. Clinical trials have proved that orlistat has a certain effect on the treatment of NAFLD without fibrosis, and show that the decrease of liver fat infiltration in obese NAFLD patients is positively correlated with the changes of serum peripherin and adiponectin levels.?

To sum up, there are a lot of studies on the mechanism and treatment of NAFLD, but the pathogenesis and targeted drugs are still unclear. The clinical basic treatment suggestion is to ensure good living habits, but there is no research on the relationship between sleep duration and NAFLD disease and the incidence of the disease. Therefore, this study conducted a cross-sectional study on the correlation between sleep duration and NAFLD disease through baseline survey and follow-up survey, and carried out a prospective study on the correlation between sleep duration and NAFLD.

\section{DISCUSSION}

The blood pressure meter was Omron model hem-752 fuzzy. The blood glucose was detected by biochemical analyzer modular P800 Roche. The HPLC column model was HPLC Bio-Rad D-10. A series of biochemical indicators such as fasting cholesterol were tested by modular E170 Roche. The B-ultrasound instrument and probe were Esaote biomedica spa. The data analysis software was SAS version 9.4. After screening and exclusion, 8554 subjects were included in the first cross-sectional study and 675 in the second prospective study. Among all subjects in the cross-sectional study, the prevalence of NAFLD was $30.41 \%$. BMI, TG, TC, LDL-C, HDL-C, FPG, HOMA-IR, glycosylated hemoglobin A1C, transaminase and other indicators of NAFLD patients were higher than those without NAFLD, and the proportion of NAFLD patients with other types of metabolic diseases was also greater than those without NAFLD.

In order to explore the effect of sleep time on NAFLD, the subjects were divided into two groups according to the length of sleep at noon and night. The subjects were divided into $(0,6),(6,7),(7,8),(8,9),(9,24)$ groups according to the number of sleep hours at night, and were divided into $0,(0,0.5)$ and $(0.5,3)$ groups according to the number of sleep hours at noon. The basic clinical characteristics of each group were analyzed and sorted out. Some data are shown in Table 1. From the basic clinical characteristics, we can know that the HDL-C index and the prevalence of hypertension were lower in the subjects with shorter sleep duration at night, but the level of insulin resistance was higher $(P<0.001)$. The subjects with longer naps had shorter sleep duration at night, lower smoking and exercise rates, higher prevalence of various metabolic diseases, higher levels of GGT, LDL-C, fasting blood glucose, TG, glycosylated hemoglobin A1C, HOMA-IR and fli $(P<0.05)$.

The subjects who sleep more than 9h at night and those who don't take midday sleep were selected as the control group of night sleep study and midday sleep study respectively. The correlation between sleep duration and NAFLD risk was analyzed. The results are shown in Table 2. Model a is only adjusted for age, gender, smoking and alcohol exercise, marriage and work conditions, model $B$ is based on model a using logistic regression analysis to adjust the parameters of transaminase, LDL-C, HDL-C, TC, BMI index, metabolic disease history and other parameters. Model a showed that the risk of NAFLD was increased by $29 \%$ - $55 \%$ in subjects with less

Table 1. Information of participants according to night sleep duration (segment).

\begin{tabular}{c|c|c|c|c|c}
\hline \multicolumn{2}{c|}{ Sleep duration/h } & $\begin{array}{c}\text { Number of } \\
\text { participants }\end{array}$ & Age(years) & BMI(kg/m²) & FLI \\
\hline \multirow{5}{*}{ Night sleep } & $(0,6]$ & 780 & $58.59 \pm 8.97$ & $25.08 \pm 3.43$ & 25.97 \\
\cline { 2 - 6 } & $(6,7]$ & 1665 & $58.16 \pm 8.69$ & $25.14 \pm 3.29$ & 25.72 \\
\cline { 2 - 6 } & $(7,8]$ & 2894 & $57.53 \pm 9.21$ & $25.15 \pm 3.35$ & 24.80 \\
\cline { 2 - 6 } & $(8,9]$ & 2159 & $58.50 \pm 9.87$ & $25.08 \pm 3.15$ & 24.83 \\
\cline { 2 - 6 } & $(9,24)$ & 1056 & $61.86 \pm 11.69$ & $24.99 \pm 3.33$ & 24.52 \\
\cline { 2 - 6 } & $P_{\text {for trend }}$ & $/$ & $<0.0001$ & 0.3515 & 0.2294 \\
\hline \multirow{5}{*}{ Daytime nap } & 0 & 5881 & $57.22 \pm 9.38$ & $25.14 \pm 3.27$ & 24.44 \\
\cline { 2 - 6 } & $(0,0.5]$ & 758 & $60.14 \pm 9.21$ & $24.94 \pm 3.20$ & 25.67 \\
\cline { 2 - 6 } & $(0.5,3)$ & 1915 & $61.90 \pm 9.88$ & $25.04 \pm 3.40$ & 26.64 \\
\cline { 2 - 6 } & $P_{\text {for trend }}$ & $/$ & $<0.0001$ & 0.1547 & $<0.0001$ \\
\hline
\end{tabular}


than 9 hours of sleep at night $(P=0.0003)$. The risk of NAFLD was $14 \%$ higher in patients who had more than half an hour of midday sleep than those who did not. Model $B$ showed that the risk of NAFLD was increased by $38 \%$ - $66 \%$ in subjects with less than 9 hours of sleep ( $P=0.0073)$, and the risk of having more than half an hour of midday sleep was $22 \%$ higher than that of those who did not. Both models showed a $6 \%$ reduction in the risk of disease for every hour of sleep increase at night. ${ }^{4}$

The correlation between sleep duration and NAFLD risk was analyzed using prospective follow-up survey data after five years. The results are shown in Table 3. Model X was uncorrected, and model C was adjusted by multivariate regression analysis based on model $\mathrm{B}$. It can be seen from Table 3 that the risk of NAFLD increased by $56 \%, 83 \%, 121 \%$ and $59 \%$ with sleep time of $(0,6),(6,7),(7,8),(8,9),(9,24)$ respectively, $P=0.0005$, while there was no statistical correlation between the length of nap and the risk of NAFLD. Cross sectional analysis and prospective analysis of the models showed that the risk of NAFLD was lower in the subjects with longer night sleep and the lack of night time was an independent risk factor for the increase in NAFLD incidence rate. The subjects with shorter nightly sleep duration had lower risk of NAFLD, but the association between noon sleep duration and NAFLD incidence was not statistically significant.

\section{CONCLUSIONS}

With the improvement of people's living conditions, NAFLD and its related metabolic diseases are gradually spreading in the world. At present, the pathogenic mechanism of NAFLD is still controversial,

Table 2. Adjusted ORs(odds rations) of NAFLD in night sleep duration and daytime nap categories.

\begin{tabular}{l|c|c|c|c|c}
\hline \multicolumn{3}{|c|}{ Sleep duration/h } & \multirow{2}{*}{$\begin{array}{c}\text { Number of } \\
\text { subjects }\end{array}$} & $\begin{array}{c}\text { Number } \\
\text { of cases }\end{array}$ & \multicolumn{2}{|c}{ Multivariate OR(95\%Cl) } \\
\cline { 5 - 6 } & $(0,6]$ & 780 & 268 & 1.52 & 1.66 \\
\hline & $(6,7]$ & 1665 & 513 & 1.30 & 1.29 \\
\cline { 2 - 6 } & $(7,8]$ & 2894 & 890 & 1.29 & 1.32 \\
\cline { 2 - 6 } & $(8,9]$ & 2159 & 656 & 1.29 & 1.38 \\
\cline { 2 - 6 } & $(9,24)$ & 1056 & 268 & 1.00 & 1.00 \\
\cline { 2 - 6 } & $P_{\text {for trend }}$ & $/$ & $/$ & 0.0008 & 0.0073 \\
\cline { 2 - 6 } & Increment/h & $/$ & $/$ & 0.94 & 0.94 \\
\hline \multirow{5}{*}{ Daytime nap } & 0 & 5881 & 1747 & 1.00 & 1.00 \\
\cline { 2 - 6 } & $(0,0.5]$ & 758 & 229 & 1.03 & 1.08 \\
\cline { 2 - 6 } & $(0.5,3)$ & 1915 & 621 & 1.11 & 1.22 \\
\hline
\end{tabular}

Table 3. Ors (odds rations) of imcident NAFLD in night sleep duration and daytime nap categories baseline.

\begin{tabular}{l|c|c|c|c|c}
\hline \multicolumn{2}{c|}{ Sleep duration/h } & \multirow{2}{*}{$\begin{array}{c}\text { Number } \\
\text { of cases }\end{array}$} & \multicolumn{3}{|c}{ Multivariate OR $(95 \% \mathrm{CI})$} \\
\cline { 4 - 6 } & & & Model X & Model B & Model C \\
\hline \multirow{5}{*}{ Night sleep } & $(0,6]$ & 51 & 1.41 & 1.60 & 1.59 \\
\cline { 2 - 6 } & $(6,7]$ & 160 & 1.99 & 2.23 & 2.21 \\
\cline { 2 - 6 } & $(7,8]$ & 247 & 1.81 & 1.84 & 1.83 \\
\cline { 2 - 6 } & $(8,9]$ & 162 & 1.50 & 1.57 & 1.56 \\
\cline { 2 - 6 } & $(9,24)$ & 55 & 1.00 & 1.00 & 1.00 \\
\cline { 2 - 6 } & $\mathrm{P}_{\text {for trend }}$ & $/$ & 0.0031 & 0.0004 & 0.0005 \\
\cline { 2 - 6 } & Increment/h & $/$ & 0.92 & 0.90 & 0.90 \\
\hline \multirow{5}{*}{ Daytime nap } & 0 & 477 & 1.00 & 1.00 & 1.00 \\
\cline { 2 - 6 } & $(0,0.5]$ & 64 & 1.10 & 1.19 & 1.15 \\
\cline { 2 - 6 } & $(0.5,3)$ & 134 & 0.98 & 1.11 & 1.08 \\
\hline
\end{tabular}

and effective treatment methods are relatively missing. The most important treatment is to ensure healthy and good living habits. In order to confirm the significance of good sleep habits in the prevention and treatment of NAFLD, a cross-sectional study and a prospective study were conducted on the subjects by means of questionnaire, biochemical test, physical fitness monitoring and ultrasonic diagnosis, in order to explore the relationship between sleep habits and NAFLD. The results of cross-sectional study showed that the risk of NAFLD increased by 38- $66 \%$ in subjects with less than 9h sleep $(P=0.0073)$, and the risk of NAFLD was $22 \%$ higher than that of non nap group $(P=0.0073)$, and the risk of NAFLD was reduced by $6 \%$ for each additional hour of sleep at night. The results of prospective study showed that the risk of NAFLD was increased by $56 \% \sim 121 \%$ in subjects with sleep time less than $9 \mathrm{~h}$ compared with those who slept longer than $9 h(P=0.0005)$. However, there was no significant correlation between nap duration and NAFLD risk. It can be seen that subjects who sleep longer at night have a lower risk of NAFLD, and those who sleep shorter in the afternoon have a lower risk of NAFLD. Therefore, in order to prevent and treat NAFLD, people should reasonably ensure adequate sleep at night and reduce midday sleep time. The subjects of this study only selected the middle-aged and elderly population in the community. In the future work, we should do further research on the relationship between sleep duration and NAFLD prevalence and incidence of more age groups.

All authors declare no potential conflict of interest related to this article

AUTHORS' CONTRIBUTIONS: The authors has completed the writing of the article or the critical review of its knowledge content. This paper can be used as the final draft of the manuscript. Each author has made an important personal contribution to this manuscript. Lixue Yin: writing and executing manuscripts. Hong Yue: data analysis and performing surgeries.

\section{REFERENCES}

1. Honma, M., Sawada, S., Ueno, Y. et al. Selective insulin resistance with differential expressions of IRS-1 and IRS-2 in human NAFLD livers. International Journal of Obesity. 2018; 42(9):1544-1555.

2. Athyros VG, Polyzos SA, Kountouras J, Katsiki N, Anagnostis P, Doumas M, Mantzoros CS. Non-Alcoholic Fatty Liver Disease Treatment in Patients with Type 2 Diabetes Mellitus; New Kids on the Block. Curr Vasc Pharmacol. 2020;18(2):172-181.

3. Mirea AM, Tack CJ, Chavakis T, Joosten LAB, Toonen EJM. IL-1 Family Cytokine Pathways Underlying NAFLD: Towards New Treatment Strategies. Trends Mol Med. 2018;24(5):458-471.

4. Perumpail BJ, Li AA, John N, Sallam S, Shah ND, Kwong W, Cholankeril G, Kim D, Ahmed A. The Role of Vitamin E in the Treatment of NAFLD. Diseases. 2018; 24;6(4):86

5. Omer S, Rakesh B, James P, Haley Bush, Pegah Golabi, Zobair M Younossi. Among Patients With NAFLD, Treatment of Dyslipidemia Does Not Reduce Cardiovascular Mortality. Hepatology Communications. 2018;2(10): 1227-1234

6. Patton A, Church T, Wilson C, et al. Phenylmethimazole abrogates diet-induced inflammation, glucose intolerance and NAFLD. J Endocrinol. 2018;237(3):337-351.

7. Ali Khan R, Kapur P, Jain A, Farah F, Bhandari U. Effect of orlistat on periostin, adiponectin, inflammatory markers and ultrasound grades of fatty liver in obese NAFLD patients. Ther Clin Risk Manag. 2017;13:139-149. 